\title{
SEISMIC VULNERABILITY ASSESSMENT METHOD FOR VERNACULAR ARCHITECTURE CONSIDERING UNCERTAINTY
}

\author{
JAVIER ORTEGA ${ }^{1 *}$, SAVVAS SALOUSTROS ${ }^{2}$, PERE ROCA $^{2}$ \\ ${ }^{1}$ ISISE Department of Civil Engineering, University of Minho \\ Campus de Azurém, 4800-058 Guimarães, Portugal \\ e-mail: javier.ortega@civil.uminho.pt (*corresponding author) \\ ${ }^{2}$ Department of Civil and Environmental Engineering \\ Universitat Politècnica de Catalunya (UPC-BarcelonaTech) \\ Jordi Girona 1-3, 08034 Barcelona, Spain \\ email: \{savvas.saloustros;pere.roca.fabregat\}@upc.edu
}

Keywords: Seismic vulnerability, Vernacular heritage, Masonry, Uncertainty, Probabilistic analysis, Pushover analysis

\begin{abstract}
Built vernacular heritage embraces buildings that are not designed by specialists, but are part of a process that involves many people over many generations and relies on empirical knowledge. Its value as a key-element for cultural identity is unquestionable. However, precisely due to its empirical and traditional nature, it is often seen as an obsolete and unsafe way of construction, which leads to its progressive abandonment. This lack of proper construction details and poor maintenance increases the seismic vulnerability of the vernacular heritage. There is an evident need for simplified easy-to-use seismic vulnerability assessment methods for vernacular architecture, given the generalized lack of resources that can be normally assigned to its study and preservation. Most of the times, visual inspection will be the only tool available to carry out the assessment.
\end{abstract}

Nevertheless, simplified methods demand a deep understanding of the seismic behavior of vernacular architecture. This is a complex task given the great heterogeneity in the geometrical, structural, construction and material characteristics of vernacular buildings. The present works explores the development of a probabilistic method for the analytical derivation of seismic fragility functions of vernacular buildings considering uncertainty in material parameters and structural characteristics. The procedure followed to investigate the effect of uncertainty and to evaluate the influence of a set of key parameters on the seismic response of vernacular buildings is based on stochastic analysis. In the end, a simplified numerical tool is proposed which can be applied based on visual inspection. The process applied and shown here is considered as an example of application and can be replicated in other contexts. It ultimately intends to extend the applicability and reliability of current seismic vulnerability assessment methods. 


\section{INTRODUCTION}

Seismic vulnerability assessment methods for the built environment play an important role on risk mitigation, as they are the main components of models capable of predicting damage to buildings and estimating losses in future earthquakes. That is why they have become a valuable tool for the preservation of the built heritage, allowing to identify the most vulnerable elements at risk. As a result, structural retrofitting strategies at an urban or regional level can be defined and optimized. This has a particular importance when dealing with the preservation of the built vernacular heritage, which is rarely represented by single structures, but usually involves a group of buildings and settlements within a region or historical city center.

Because of its empirical and traditional nature, vernacular architecture is considered in many places as an obsolete way of building and only valued as part of the region's identity [1]. Typically, people tend to see vernacular construction technologies as unsafe and eventually abandon and substitute them with modern ones. The risk of vernacular heritage to disappear due to a global economic, cultural, and architectural homogenization was already highlighted by ICOMOS [1]. As a result of this progressive abandonment, there is also an increasing vulnerability of vernacular architecture facing natural hazards, including earthquakes.

There is also a typical lack of resources assigned to the study and preservation of the vernacular heritage. When dealing with monumental architecture, many sophisticated tools are available, such as non-destructive evaluation techniques and advanced structural analysis methods. Moreover, monuments are typically well documented and historical research can

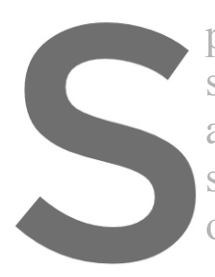
provide a significant amount of information of the structure. I
seismic safety of vernacular architecture, visual inspection v
available. Thus, seismic vulnerability assessnent methods t
should be easy-to-use and make use of qualitative or simple qu
obtained from simple visual inspections. Additionally, being ernacular architecture deeply
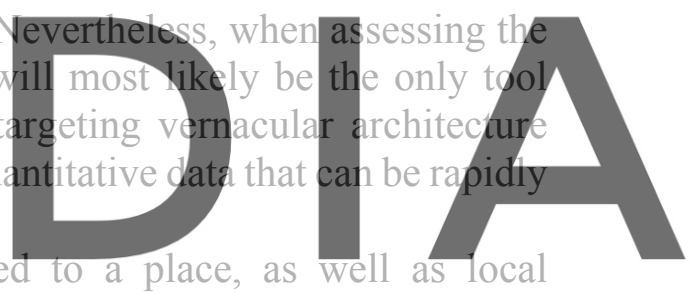
traditional construction techniques and materials, it typically shows great heterogeneity in terms

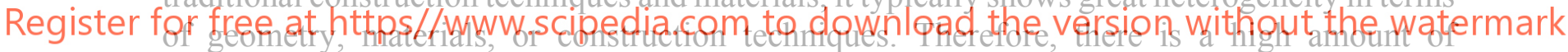

uncertainty in the characterization of the geometry and morphology of the structural elements, as well as the mechanical parameters of the constituent materials. Unknown parameters showing a high variability include masonry material properties, diaphragm type and quality of wall-to-floor connections, or quality of wall-to-wall connections.

Given the preceding challenges (i.e. lack of resources and the structural heterogeneity), the present work intends to explore the development of a seismic vulnerability assessment method adequate for vernacular constructions. Previous works by the authors have proposed to use finite element modeling and pushover analysis to evaluate the influence of a set of key parameters on the seismic response of vernacular buildings. As a result, a simplified numerical tool was developed particularly intended to assess the seismic vulnerability of vernacular buildings [3]. However, the final developed tool did not consider the high amount of uncertainty in the definition of geometrical, structural and material parameters of vernacular architecture. The present work explores a probabilistic methodology for the analytical derivation of seismic fragility functions of vernacular buildings including uncertainty in materials and construction characteristics. The procedure followed to investigate the effect of uncertainty in the proposed method is based on stochastic analysis previously applied for the assessment of masonry 
structures [4][5]. This approach is meant to extend the applicability and reliability of the seismic vulnerability assessment method previously developed by considering uncertainty in structural characteristics and material properties.

\section{PROBABILISTIC ASSESSMENT}

The present work shows an example of the procedure proposed to perform the seismic vulnerability assessment for vernacular constructions. The city of Vila Real de Santo António (VRSA) is used as a case study. VRSA is located in Algarve, the southernmost area of Portugal. This region was considerably affected by the 1755 Lisbon earthquake and was practically abandoned at the time. As an attempt to boost the Algarve local economy through industrial development, the Marquis of Pombal enacted an official recovery program during the 1760s and 1770s that included the construction from scratch of the city of VRSA. Despite the important transformation process in the city since its construction, the Pombaline city center still show a certain degree of homogeneity.

The proposed procedure to develop the seismic vulnerability assessment method consists of the following seven steps: (1) definition of a reference representative example of the vernacular typology under study in terms of geometry and construction, selection of the uncertain parameters and definition of ranges of variation for each parameter; (2) preparation of numerical finite element models according to the reference example and parameters under study; (3) definition of probabilistic distribution for each selected parameter; (4) stochastic analysis to create a representative sample; (5) seismic analysis, based on the finite element method and nonlinear static (pushovor) analysis, of the whole sample; (6) construction of
fragility curves based on the numerical analys s performed; and (7) regression analysis on the
results database to obtain analytical expressions that allow deriving fragility curves withoyt the
need of performing numerical analysis.
Once the regression expressions are formulated for the studied typology, they can be used Once the regression expressions are formulated for the studied typology, they can be used
for several purposes, such as: (a) to perform a new seismic vulnerability assessment on an

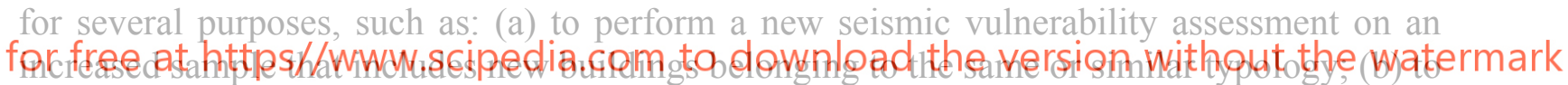

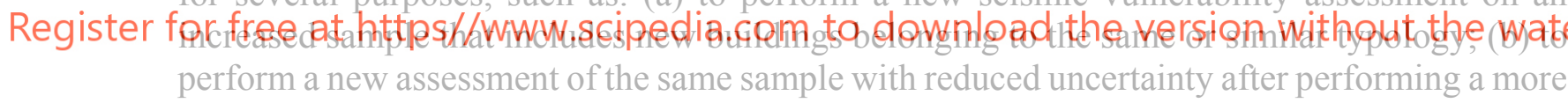
detailed inspection or non-destructive evaluation of some buildings; or (c) to study the effect of different retrofitting strategies on the seismic vulnerability of the sample. Moreover, the procedure proposed and shown in the present work allows its replication to other contexts. Indeed, the application of the same procedure to other contexts and typology can enlarge and make a more comprehensive database allowing the update of the regression expressions.

\subsection{Case study and unknown variables}

The structural system of the original built-up environment of VRSA mainly consisted of load-bearing stone masonry walls as the main vertical resisting elements, coupled with horizontal timber diaphragms (floors and roofs). Nowadays, the great majority of the original buildings have been replaced by new ones or are highly altered at a formal and structural level. The original single-story dwellings were the main target of the demolitions, substitutions and large modifications. The most common modifications included the addition of new floors, the enlargement or addition of new openings or the substitution of the timber floors and roofs. The deep mischaracterization of the built-up environment is not only detrimental in terms of loss of 
authenticity of an important architectural and urban heritage, but also reflects the loss of seismic awareness, having an important impact on the seismic vulnerability of the buildings [6].

There are currently 284 stone masonry buildings in VRSA city center ( 7 of them original unaltered buildings) [6]. Figure 1 shows two original single-story dwellings that were altered with the addition of a second floor. Detailed reports on the construction characteristics and state of conservation of most of the buildings [7] are available, which allowed to define a representative reference model, using average dimensions and following the typical construction characteristics.

The present work shows a first example of the application of the proposed methodology for estimating the seismic vulnerability of vernacular buildings at urban scale. In this case, six uncertain parameters were considered as random variables. Four of them are related to the material mechanical parameters of the masonry walls (Figure $2-$ left). These are the tensile and compressive strength, the Young's modulus, and the tensile fracture energy of the masonry walls. The other two are related with structural characteristics of the buildings: the type of diaphragm and quality of floor-to-wall connection (Figure 2- middle); and the quality of wallto-wall connections (Figure 2 - right).
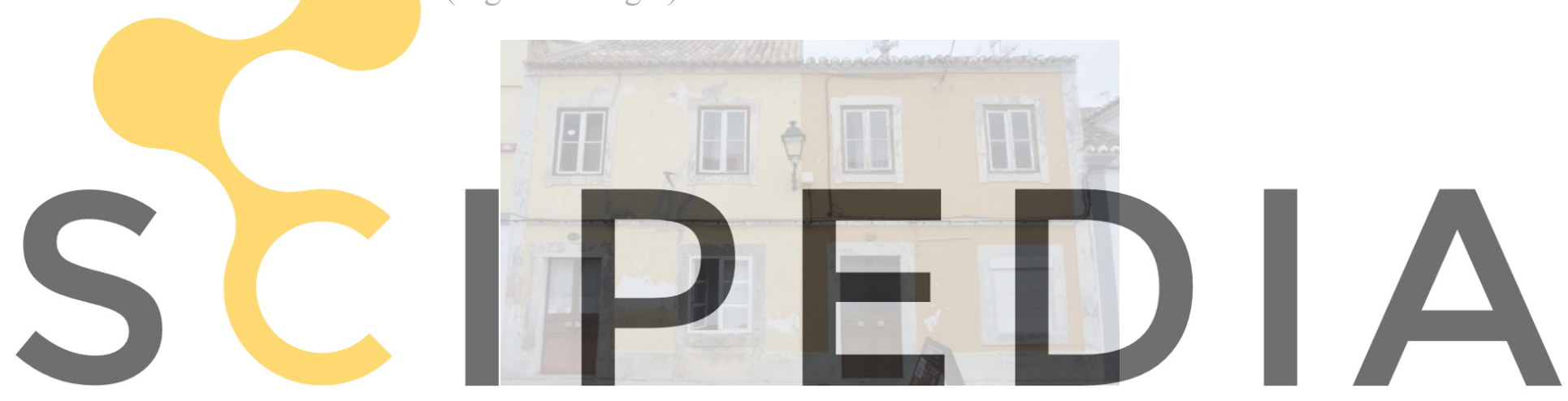

Figure 1: Two vernacular buildings in the historical city center of Vila Real de Santo António.

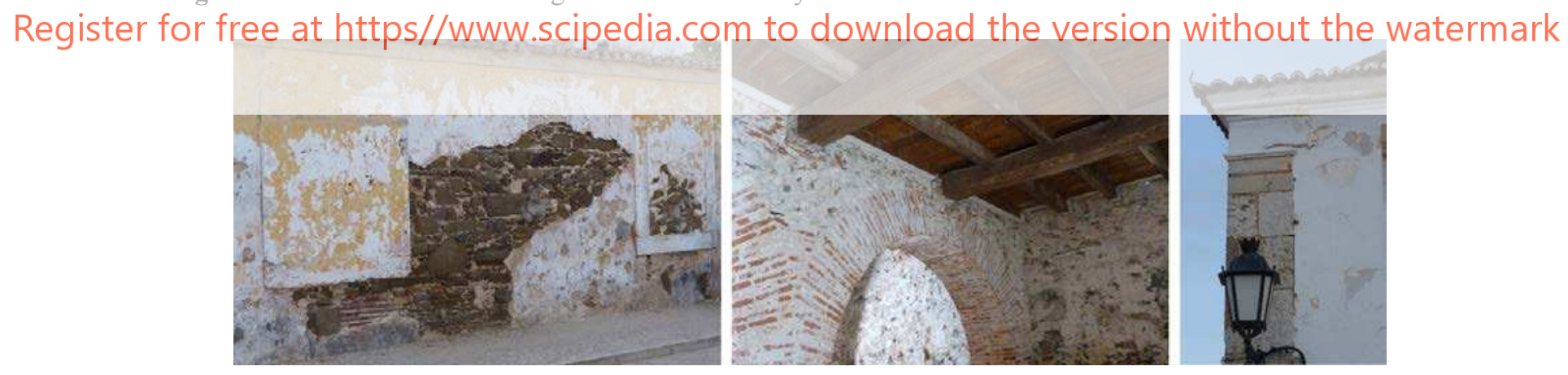

Figure 2: Typical constructive details observed in Vila Real de Santo António: (left) masonry morphology; (middle) diaphragm type; (right) wall-to-wall connections.

\subsection{Numerical model}

After the definition of a reference representative example of the vernacular typology, numerical finite element models were prepared. The reference models were prepared in a generic way to easily accommodate the variations required to assess the influence of the different parameters. The software selected to perform the numerical parametric analysis was 
DIANA [8]. Three models were created assuming different types of diaphragm and floor-towall connection (Figure 3) with general dimensions of $8 \mathrm{~m} \times 5.5 \mathrm{~m} \times 5.2 \mathrm{~m}$ (length $\mathrm{x}$ width $\mathrm{x}$ height). All elements are simulated with ten-node isoparametric 3D solid tetrahedron elements (CTE30), with four-point integration scheme over the volume.

Masonry with varying material properties is considered for the walls. The properties of the masonry at the corners (in red in Figure 3) is also varied, assuming different levels of quality of wall-to-wall connections. Timber is used for the lintels and floor construction elements. Only the materials used for the walls are considered to present nonlinear behavior, adopting standard isotropic Total Strain Rotating Crack Model (TSRCM) [8].
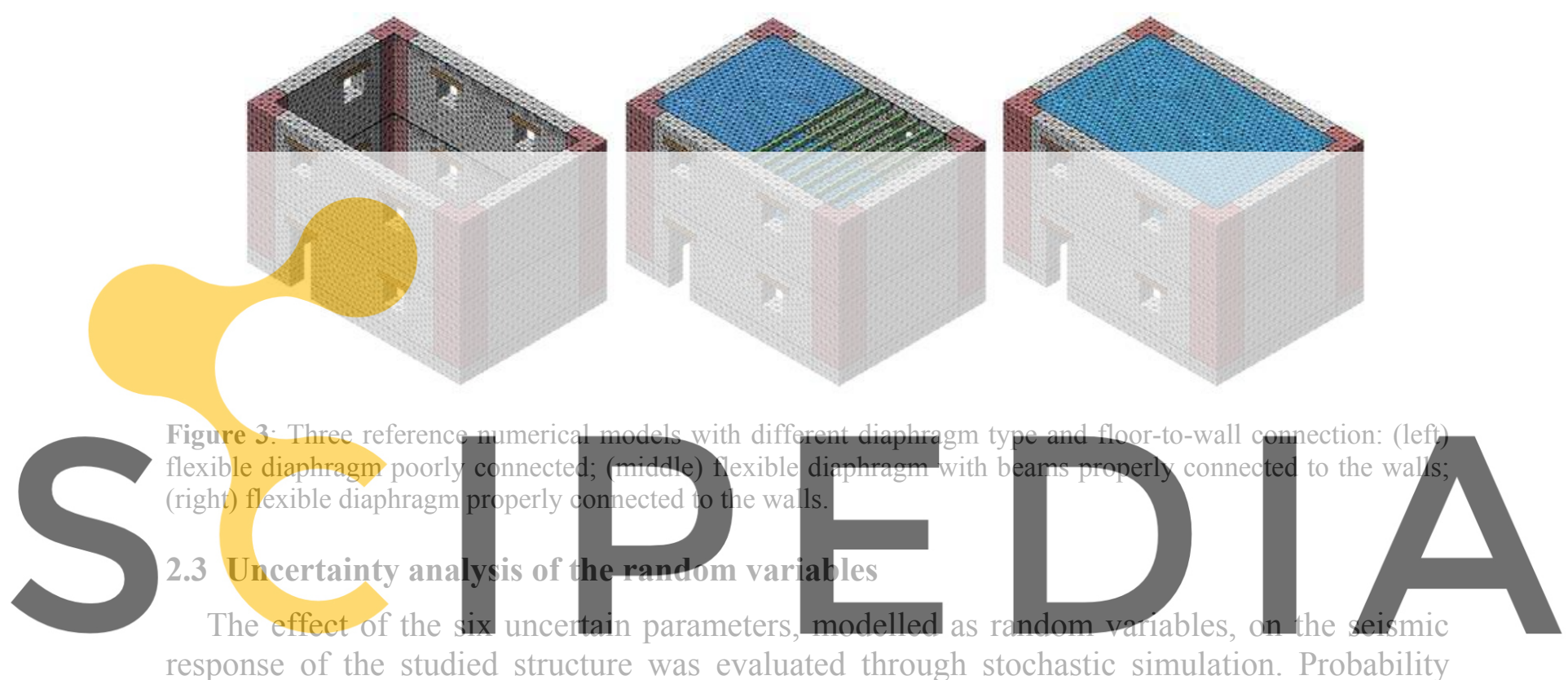

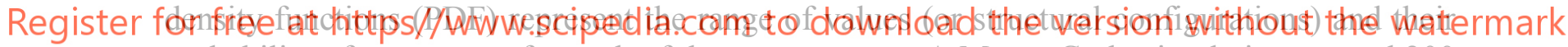
probability of occurrence for each of these parameters. A Monte Carlo simulation created 200 random combinations of these random variables, which correspond to the same number of numerical models. The sample number is based on previous experience [4,5]. Additionally, a Latin Hypercube sampling approach was employed to improve the efficiency of the sampling process. Figure 4 presents the results of the sampling procedure for the six random variables.

The variation of Young's modulus $(E)$, compressive strength $(f c)$ and tensile strength $(f t)$ was defined using lognormal distributions, in line with the recommendations of CNR-DT $212 / 2013$ [9][1]. The values of the mean $(\mu)$ and the standard deviation of the logarithm $(\sigma l n)$ for the Young's modulus $\left(\mu=1740 \mathrm{MPa}, \sigma_{l n}=0.14\right)$ and the compressive strength $(\mu=3.2 \mathrm{MPa}$, $\sigma_{l n}=0.19$ ) correspond to the values for an "uncut stone masonry with good texture" typology in [9], which is considered adequate for the current case study [6]. The tensile strength is a more difficult parameter to obtain experimentally and is usually defined as a fraction of the compressive strength. A mean value of $\mu=0.06 \mathrm{MPa}$ and a standard deviation equal to the one used for the compressive strength $\left(\sigma_{l n}=0.19\right)$ were assumed. The resulting ratio between tensile and compressive strength for all the cases varies between 0.01 and 0.04 . Concerning the tensile fracture energy, there is limited experimental information. Only rough assessments about its 
variation intervals can be provided. Thus, the variation was defined using a uniform distribution with the upper and lower limits being 10 and $100 \mathrm{~N} / \mathrm{mm}$, respectively.

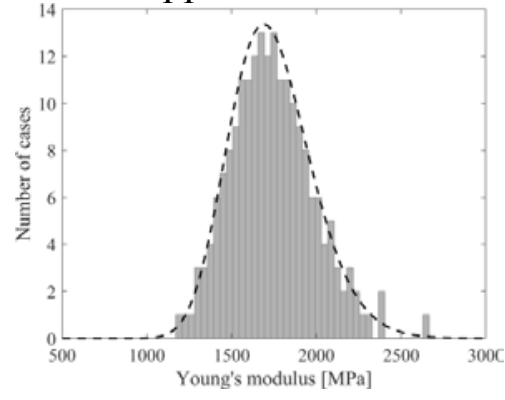

(a)

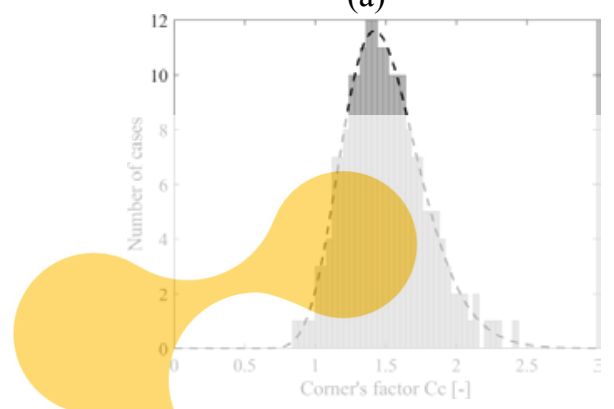

(d)

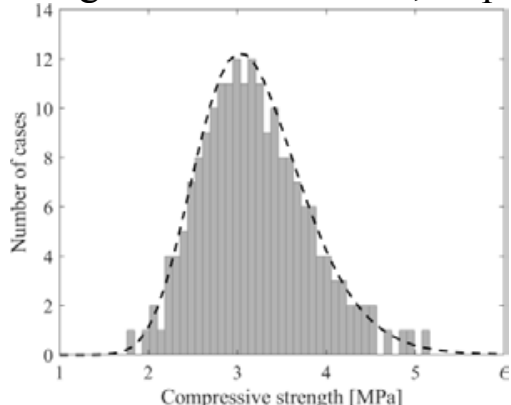

(b)

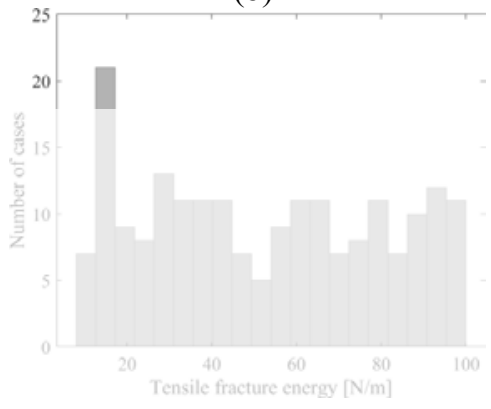

(e)

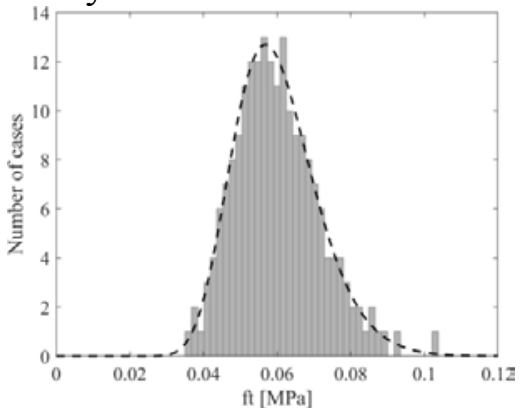

(c)

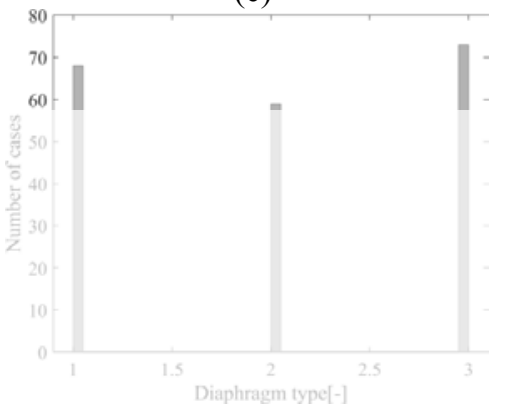

(f)

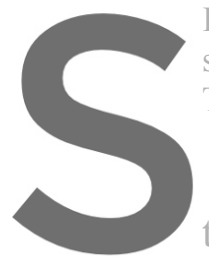

Figure 4: Histograms with

strength $f_{c},(c)$ Tensile/comp

Type of diaphragm (1: Embedded b

The other two random variale

to-wall connections and the qual

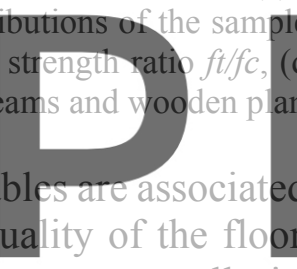

pled vaiues of: (a) Young's modulus E, (b)
(d) Corner's coefficient Cc, (e) Fracture En
anks, 2: Embedded beams, 3: No-diaphragm
ed with structural details; the quality
or-to-wall connection. Regarding the

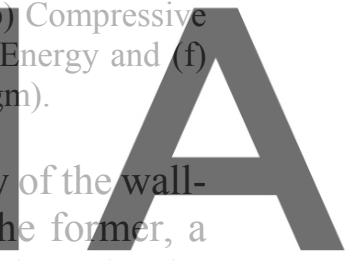

good interlocking between transverse walls is possible when special care is given in the

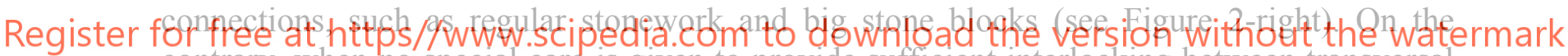
contrary, when no special care is given to provide sufficient interlocking between transversal walls, these connections become one of the most vulnerable parts of the structure and their capacity compromises the structural behavior. To account for this important structural characteristic, the mechanical properties of the masonry at the corners of the building were considered as proportional to the chosen values for the masonry walls through a proportionality factor $C c$. In this way, the mechanical properties of the corners were defined with a single variable, instead of one for each mechanical property. For the particular case study, the large stone blocks seen in the corners of many buildings indicate overall good wall-to-wall connections. Accordingly, it can be assumed that the masonry quality of the corners will be in average better than that of the rest of the walls. This feature was considered in the assessment by using a mean value $\mu=1.5$ for the proportionality coefficient $C c$, indicating a $50 \%$ higher properties in the masonry at the corners as an average. The standard deviation of the proportionality factor $\mathrm{Cc}$ was defined equal to that used for the compressive strength $\left(\sigma_{l n}=0.19\right)$.

The last random variable concerns the diaphragmatic action of the floors and three scenarios were considered. In the worst-case scenario, there is no diaphragmatic action due to the poor connection between the floors and the walls. The second scenario considers an improved diaphragmatic action of the floor due to the proper embedment of the beams within the façade 
walls. Finally, in the best-case scenario, the floor beams are properly embedded in the façade walls and the floor wooden planks contribute to the stiffness of the floor. These three cases were simulated by adopting three modelling strategies for the floor (Figure 3). For the first scenario, the structural model does not include the floors. For the second scenario, the floor beams are embedded up to the half of the wall's length. The same assumption holds for the last scenario including also the modelling of the wooden planks. As a first attempt, considering a scenario without a proper inspection of the interior of the buildings, a uniform distribution was used to represent the equal possibility of having any of the above cases in a vernacular building in VRSA.

Regarding the rest of the material parameters, the compressive fracture energy of masonry was defined as $G f c=1.6 f c$ according to [10]. The timber beams and floors were modelled as linear elastic with Young's modulus equal to $10 \mathrm{GPa}$ and Poisson's ratio of 0.3. Poisson's ratio of 0.20 was used for the masonry walls.

\subsection{Seismic analysis}

Figure 5 presents the capacity curves (horizontal acceleration vs displacement) for the 200 numerical models analyzed with different combinations of the random variables. The analyses show a large range of the maximum acceleration, varying approximately between $0.25 \mathrm{~g}$ and $1.3 \mathrm{~g}$. It is easy to observe two families of capacity curves, one with notably higher strength capacity and stiffness than the second. The use of three line types and colors, corresponding to

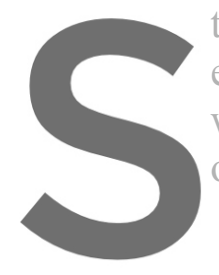
the floor-to-wall coninect effect on the seismic r with a grey continuous of the cases.
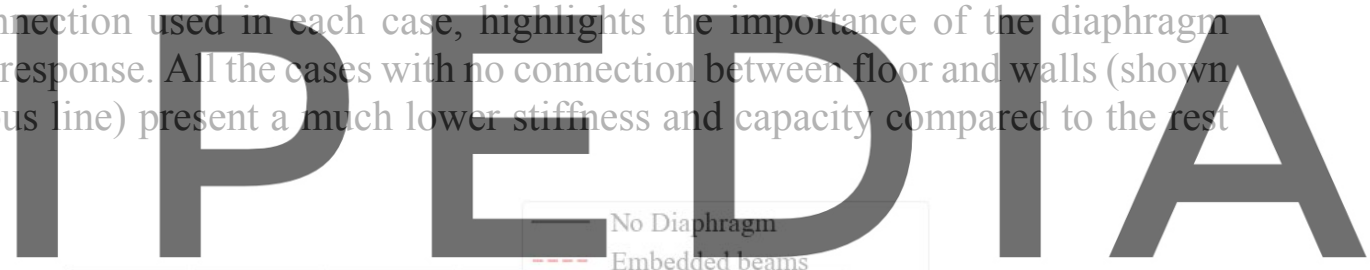

Register for free at https//www.scipedía.com to download the version without the watermark

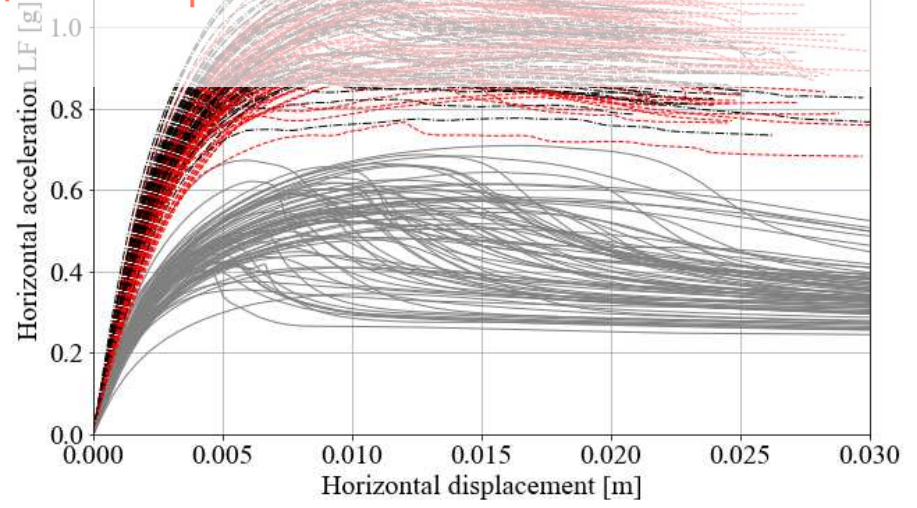

Figure 5: Pushover capacity curves obtained corresponding to the 200 analysis with different combinations of six random variables (colors according to diaphragm type considered in the analysis).

The change in the type of diaphragm results in a different failure mechanism, as shown in Figure 6, presenting three representative cases for each of the defined wall-to-diaphragm types. The lack of any diaphragmatic action provokes local mechanisms characterized mainly by the 
out-of-plane failure of the façade. This failure mechanism is not observed when the diaphragm is assumed to be well connected with the two facades. For these cases, the structure presents a more global response against the seismic action.

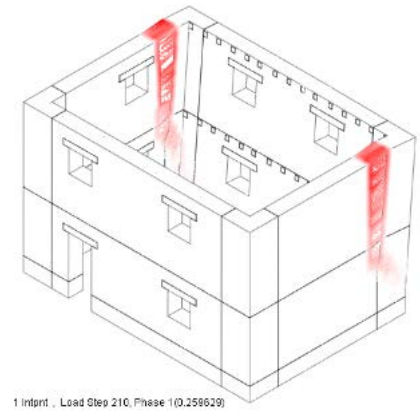

(a)

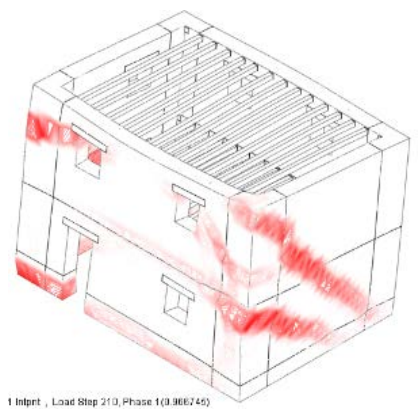

(b)

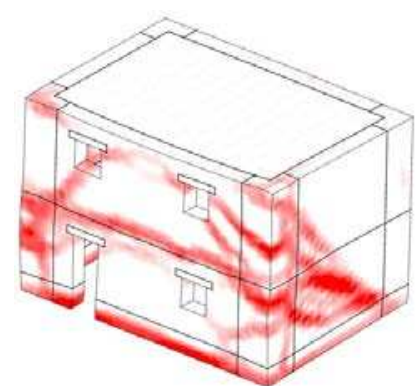

(c)

Figure 6: Principal crack strains for different types of diaphragm: (a) no diaphragmatic action, (b) embedded beams, (c) embedded beams and wooden planks

\subsection{Fragility curves}

The seismic vulnerability of the studied vernacular buildings can be expressed through the following fragility function [11]:

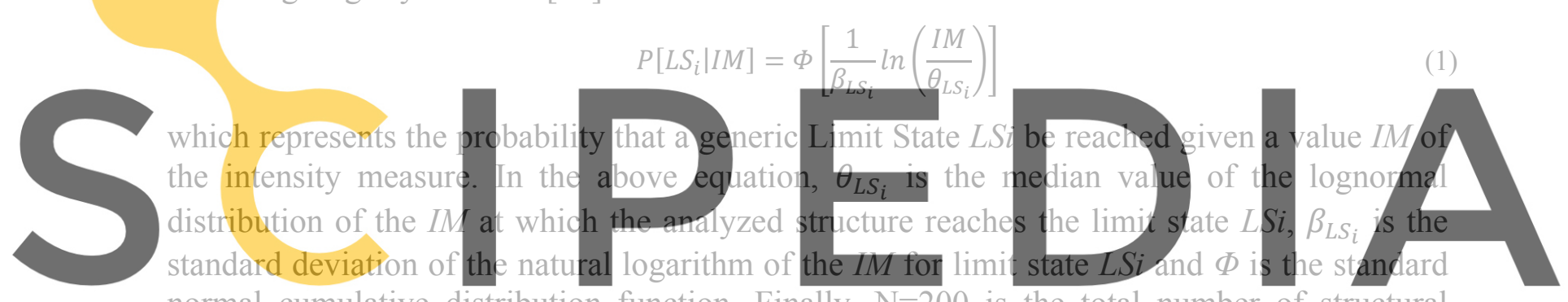

normal cumulative distribution function. Finally, $N=200$ is the total number of structural

Register for fysis carried out In this work, the fragility curves are obtained for the Limit State LS3, as defined in [3,6], corresponding to a life safety limit state. LS3 is defined in $[3,6]$ in terms of the horizontal acceleration and displacement obtained from a pushover analysis that correspond to the maximum strength of the building. As a first step in the proposed methodology, the maximum horizontal acceleration computed by each pushover analysis was considered as the intensity measure. The use of this measure instead of other common intensity measures (e.g. macroseismic intensity, Peak Ground Acceleration, spectral acceleration Sa, etc.) aims to serve as a simple indicator that facilitates the comparative assessment of the capacity of the individual buildings, as will be shown in Section 3.

Figure 7 presents the fragility curves corresponding to $L S 3$ obtained by considering all the 200 analyzed cases, as well as three more curves that were obtained considering: i) only the cases without a floor-to-wall connection; ii) only the cases with embedded beams; and iii) only the cases with embedded beams and wood planks. It can be again seen how the absence of a diaphragm drops the strength capacity of the structure, affecting the estimations of the fragility of all the population. These graphs clearly indicate that the implementation of wooden planks would be beneficial for the capacity of the investigated buildings, which was not so easily distinguishable in Figure 5. 


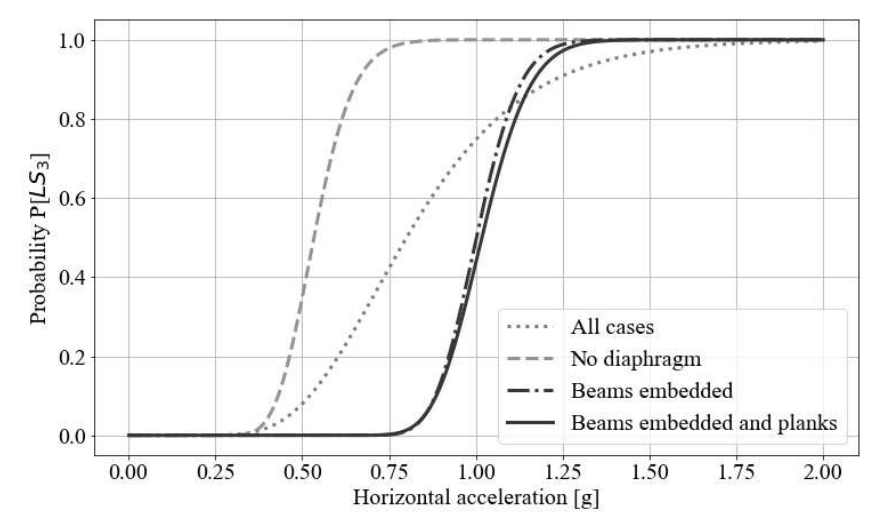

Figure 7: Fragility curves corresponding to Limit State 3 (maximum strength capacity) against horizontal acceleration obtained from the pushover analyses. The different lines correspond to different populations related with the floor-towall connection assumption.

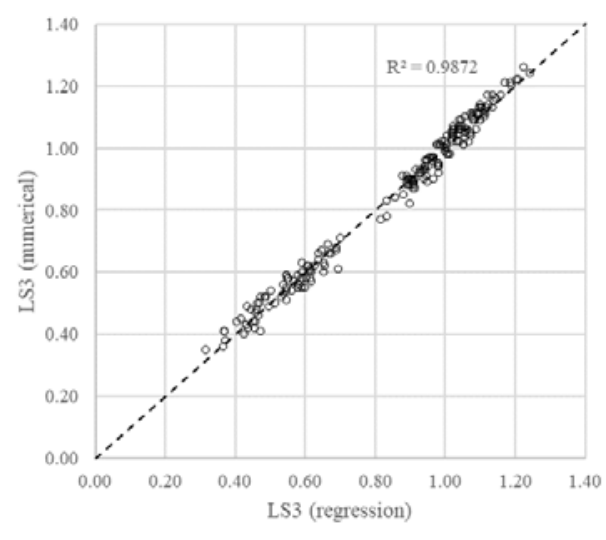

Figure 8: $L S 3$ predicted (regression) vs observed (numerical).

\subsection{Regression analysis and empirical Expressions}

The statistical analysis and the definition of the regression models are carried out by using R open source software [12]. Multiple linear regression (MR) was applied, intended to investigate the dependence of the maximum seismic capacity of the building (LS3) on the six parameter variables sclected: (1) four material parameters ( $E$,
(Dia); and (3) quality of wall-to-wall connection $(C c)$. As a
obtained to define and quantify the relationship among them th
variables is often very complex and the simplest approach
equation to the data:
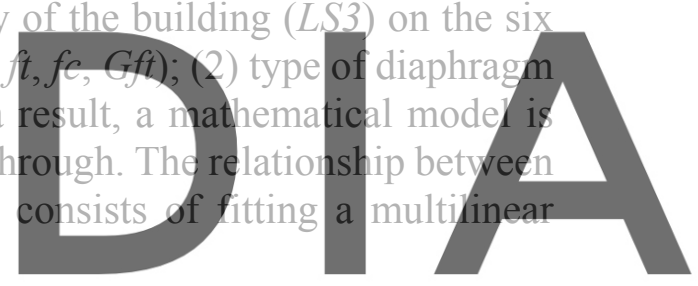

$Y=\beta_{0}+\beta_{1} x_{1}+\beta_{2} x_{2}$

Register for free at https//www scipedia.com to download the version without the watermark

parameters $\beta_{k}$ are called the regression coefficients and $\varepsilon$ is the error. The line defined by Eq.

(2) describes how the response changes according to the explanatory variables.

Before carrying out the analysis, all the parameter values were normalized by dividing every value of each parameter by the maximum value among the $\mathrm{N}=200$ values from the sampling. It should be noted that the regression model constructed excluded the intercept and after some trials also excluded the parameter $f c$, which was shown to have no statistical influence. The remaining five variables were found to be statistically significant in the prediction of the maximum capacity of the building, i.e. the maximum load factor obtained in the pushover analysis. The final regression resulted in the following regression equation:

$$
L S 3=0.099 E+0.391 f t+0.262 G f+0.3101 c+1.907 D i a-1.988 D_{i a^{2}}
$$

Note that the regression equation includes a quadratic term for the parameter Dia because the relationship between $L S 3$ and Dia was observed to be nonlinear. The mean absolute error (MAE) of the model is $0.023 \mathrm{~g}$ and the maximum absolute error is $0.085 \mathrm{~g}$. The coefficient of determination or adjusted R-squared is 0.9872 , which illustrates that the regression equation is able to match very well the numerical data, see Figure 8 . 


\section{APPLICATION AND VALIDATION}

The present section shows an example on how the regression expression from Eq. (3) could be used after it has been defined for the estimation of the seismic vulnerability of the selected case study. Previously, the probabilistic distributions were defined assuming that there was a lack specific information about the buildings. All the information was assumed to be based on simple exterior visual inspection. This section investigates the use of the expression from Eq. (3) after a second assessment has been performed on the buildings, including a more detailed visual inspection (including the interior) and non-destructive testing. The new information allows the definition of new probabilistic distributions of the random variables. In this case, the fragility function of $L S 3$ will be defined using the expression from Eq. (3). The validity of these blind predictions will be assessed afterwards through a comparison with the results of a new set of numerical analysis corresponding to the updated set of random variables.

\subsection{Updated PDFs}

Concerning the six uncertain parameter variables selected, the following hypotheses were considered to allow a better characterization and new updated probabilistic distributions. Three possible scenarios are investigated that would reduce the uncertainty of some of the selected parameters. In the case of the material properties, non-destructive evaluation techniques, namely sonic tests, can be performed on buildings to obtain a more representative distribution. Here, it is assumed that the use of sonic tests on the masonry walls allowed a better accuracy in the estimation of the nean value and the rariation of the Y oung's modulus of the masonry wal/s $\left(\mu=2000 \mathrm{MPa}, \sigma_{\ln }=0.05\right)$ more detailed inspection connections and define a with $\mu=1.8$ and $\sigma \ln =0.09$
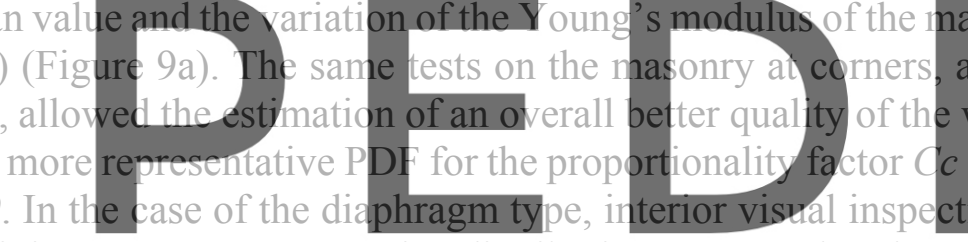

buildings can allow obtaining a more representative distribution compared to the assumed one.

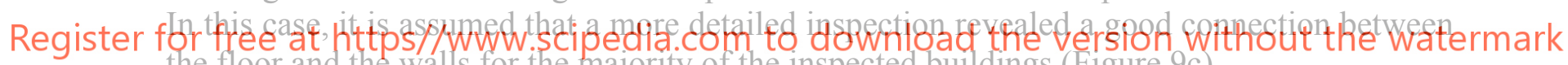
the floor and the walls for the majority of the inspected buildings (Figure 9c).

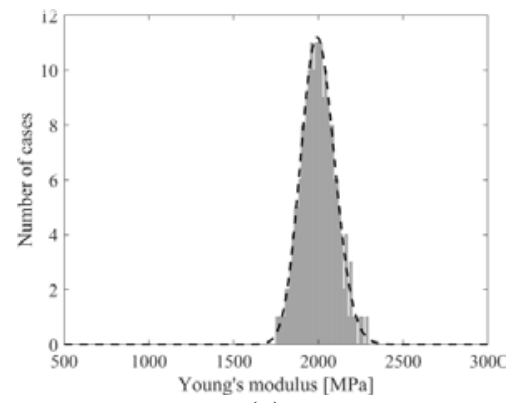

(a)

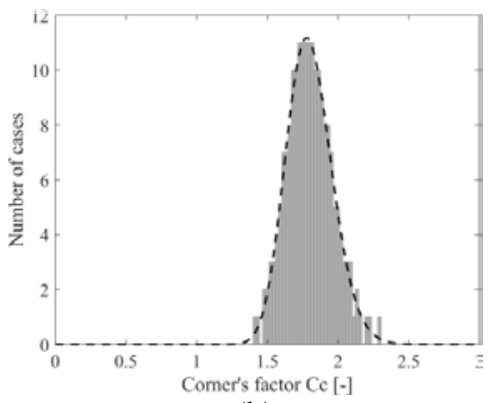

(b)

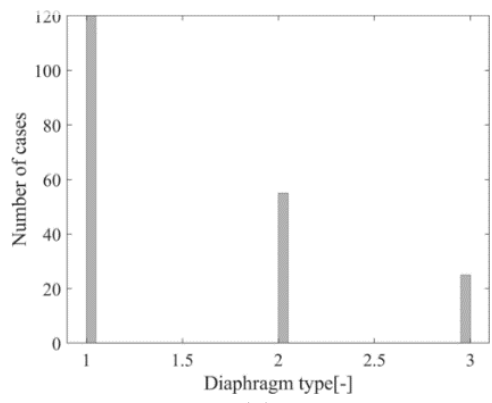

(c)

Figure 9: Updated probabilistic distributions of: (a) Young's modulus; (b) Corner's coefficient Cc, and (c) Diaphragm type (1: Embedded beams and wooden planks, 2: Embedded beams, 3: No-diaphragm). 


\subsection{Estimation of fragility and validation}

Figure 10a presents a comparison of the fragility curve corresponding to $L S 3$ before and after the update of the probability density functions (PDFs), following the scenarios of an improved in-situ inspection. The improvement of the mechanical properties of the masonry at walls and corners and the increase of the number of cases with a good floor-to-wall connection decreases notably the vulnerability of the buildings. The comparison of the fragility curve obtained using the $L S 3$ from Eq. (3) and the $L S 3$ from the new set of the pushover analyses corresponding to the updated PDFs shows a good correlation between numerical and empirical results. This is further demonstrated in Figure 10b, presenting a direct comparison of the $L S 3$ obtained with the two methods. The regression expression fits well the numerical results with a mean absolute error of $0.025 \mathrm{~g}$ and a maximum absolute error of $0.088 \mathrm{~g}$. The coefficient of determination or adjusted R-squared is 0.981 (Figure 10b), validating the procedure and the expression obtained.

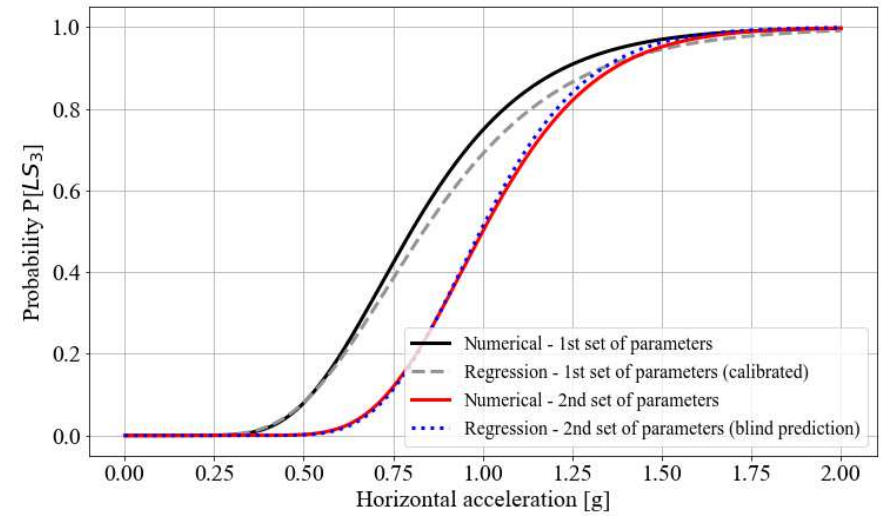

(a)

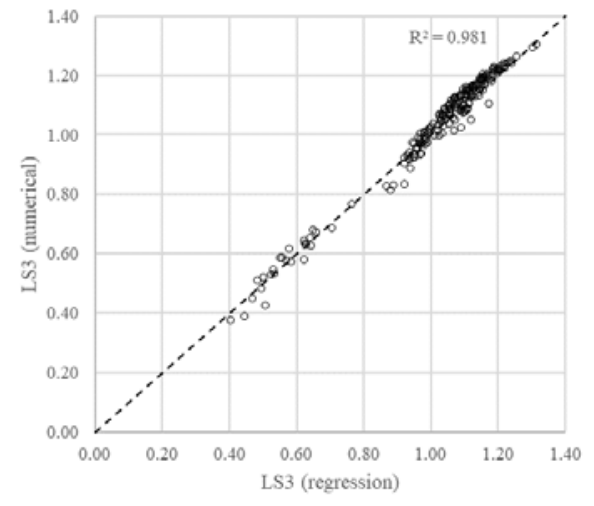

(b)

Figure 10: (a) Comparison of the fragility curves corresponding to LS3 before and after updating the PDFs of the random variables. (b) $L S 3$ predicted vs observed for the new sample of analysis (blind prediction).

\section{CONCLUSIONS}

This paper has presented the development and application of a probabilistic method for the seismic vulnerability assessment of vernacular architecture. The method aims to confront some major challenges that arise when dealing with vernacular heritage, such as the lack of resources and the structural heterogeneity. With that purpose, the method aims first to develop a simple numerical tool that provides an estimation of the seismic vulnerability of a building based on qualitative and simple quantitative data that can be obtained through visual inspection. Secondly, the proposed method explores the inclusion of uncertainty in materials and construction variables, aiming to reflect the characteristic heterogeneity of the vernacular heritage.

The method proposed has been described showing the step-by-step procedure used to carry out the seismic vulnerability assessment. The historical city center of Vila Real de Santo António (Portugal) has been considered as a case study. The proposed methodology has been validated by comparing the results obtained using the resulting regression expression with numerical results. The good correlation between numerical and empirical results illustrates the applicability of the method. 
Acknowledgements. The authors gratefully acknowledge the financial support from the Ministry of Science, Innovation and Universities (MCIU) of the Spanish Government, the State Agency of Research (AEI) and the European Regional Development Fund (ERDF) through the SEVERUS project (Multilevel evaluation of seismic vulnerability and risk mitigation of masonry buildings in resilient historical urban centres, ref. num. RTI2018-099589-B-I00).

\section{REFERENCES}

[1] Correia M. Experiences from past for today's challenges. In: The road to sustainable development. Chapter 6 - Traditional and generational change, La Fábrica, Fundación Contemporánea (2017), pp. 128-133.

[2] ICOMOS. Charter on the built vernacular heritage. International Council of Monuments and Sites (ICOMOS), ICOMOS $12^{\text {th }}$ General Assembly, Mexico (1999).

[3] Ortega, J., Vasconcelos, G., Rodrigues, H., Correia, M. and Miranda, T. Development of a Numerical Tool for the Seismic Vulnerability Assessment of Vernacular Architecture. Journal of Earthquake Engineering (2019).

[4] Saloustros, S., Pelà, F.L., Contrafatto, P., Roca, P. and Petromichelakis, I. Analytical derivation of seismic fragility curves for historical masonry structures based on stochastic analysis of uncertain material parameters. International Journal of Architectural Heritage (2019).

[5] Petromichelakis, I. and Saloustros, S. Seismic assessment of historical masonry construction including uncertainty. In: Cunha Á, Caetano E, Ribeiro P, Müller G (eds) 9th Int. Conf. Struct. Dyn. EURODYN 2014, Porto (Portugal) (2014), pp. 297-304.

[6] Ortega, J., Vasconcelos, G., Rodrigues, H. and Correia, M. Seismic Vulnerability and Loss Assessment of Vila Real de Santo António, Portugal: Application of a Novel Method. International Journal of Architectural Heritage (2020).

[7] SGU. Plano de Pormenor de Salvaguarda do Núcleo Pombalino de Vila Real de Santo António, Sociedade de Gestão Urbana (SGU) de Vila Real de Santo António. Vila Real de Santo António, Portugal (2008).

[8] TNO. Displacement method analyser. User's manual, release 9.4.4. TNO DIANA BV, Delft, Netherlands (2011).

[9] CNR-DT 212/2013. Guide for the Probabilistic Assessment of the Seismic Safety of Existing Buildings. Rome, Italy: 2014.

[10] Angelillo M, Lourenço PB, Milani G. Masonry behaviour and modelling. Mech. Mason. Struct., vol. 551, 2014. doi:10.1007/978-3-7091-1774-3.

[11] Federal Emergency Management Agency. HAZUS-MH MR4: Technical Manual, Vol. Earthquake Model. Washington DC: 2010.

[12] R Development Core Team. $R$ : A language and environment for statistical computing. $\mathrm{R}$ Foundation for Statistical Computing, Vienna, Austria (2008). 